\title{
Preparation and evaluation of a self-nanoemulsifying drug delivery system loaded with Akebia saponin D-phospholipid complex
}

This article was published in the following Dove Press journal:

International Journal of Nanomedicine

26 September 2016

Number of times this article has been viewed

Jinyang Shen,' Jianping $\mathrm{Bi}^{2}{ }^{2}$ Hongli Tian, ' Ye Jin, ' Yuan Wang, ${ }^{3}$ Xiaolin Yang, ${ }^{4}$ Zhonglin Yang,' Junping Kou, ${ }^{5}$ Fei Li'

'State Key Laboratory of Natural Medicines, China Pharmaceutical University, Nanjing, ${ }^{2}$ Shandong Provincial Traditional Chinese Medical Hospital \& Affiliated Hospital of Shandong University of Traditional Chinese Medicine, Jinan, ${ }^{3}$ Traditional Chinese Medical Hospital of Pukou District, ${ }^{4}$ Key Laboratory of Pharmaceutical and Biological Marine Resources Research and Development of Jiangsu Province, Nanjing University of Chinese Medicine, ${ }^{5}$ Jiangsu Key Laboratory of TCM Evaluation and Translational Research, Department of Complex Prescription of TCM, China Pharmaceutical University, Nanjing, People's Republic of China

Correspondence: Fei Li State Key Laboratory of Natural Medicines, China Pharmaceutical University, No 24 Tongjia Lane, Nanjing 210009, People's Republic of China $\mathrm{Tel} / \mathrm{fax}+86258327$ I 382

Email lifeicpu@I63.com

Junping Kou Jiangsu Key Laboratory of TCM

Evaluation and Translational Research, Department of Complex Prescription of TCM, China Pharmaceutical University, 639 Longmian Road, Nanjing 21 II98,

People's Republic of China

Tel/fax +86 $2586 / 85158$

Email junpingkou@cpu.edu.cn
Background: Akebia saponin D (ASD) exerts various pharmacological activities but with poor oral bioavailability. In this study, a self-nanoemulsifying drug delivery system (SNEDDS) based on the drug-phospholipid complex technique was developed to improve the oral absorption of ASD.

Methods: ASD-phospholipid complex (APC) was prepared using a solvent-evaporation method and characterized by infrared spectroscopy, differential scanning calorimetry, morphology observation, and solubility test. Oil and cosurfactant were selected according to their ability to dissolve APC, while surfactant was chosen based on its emulsification efficiency in SNEDDS. Pseudoternary phase diagrams were constructed to determine the optimized APC-SNEDDS formulation, which was characterized by droplet size determination, zeta potential determination, and morphology observation. Robustness to dilution and thermodynamic stability of optimized formulation were also evaluated. Subsequently, pharmacokinetic parameters and oral bioavailability of ASD, APC, and APC-SNEDDS were investigated in rats.

Results: The liposolubility significantly increased 11.4-fold after formation of APC, which was verified by the solubility test in $n$-octanol. Peceol (Glyceryl monooleate [type 40]), Cremophor ${ }^{\circledR}$ EL (Polyoxyl 35 castor oil), and Transcutol HP (Diethylene glycol monoethyl ether) were selected as oil, surfactant, and cosurfactant, respectively. The optimal formulation was composed of Glyceryl monooleate (type 40), Polyoxyl 35 castor oil, Diethylene glycol monoethyl ether, and APC (1:4.5:4.5:1.74, w/w/w/w), which showed a particle size of 148.0 $\pm 2.7 \mathrm{~nm}$ and a zeta potential of $-13.7 \pm 0.92 \mathrm{mV}$ after dilution with distilled water at a ratio of $1: 100(\mathrm{w} / \mathrm{w})$ and good colloidal stability. Pharmacokinetic studies showed that APC-SNEDDS exhibited a significantly greater $C_{\max } 1(733.4 \pm 203.8 \mathrm{ng} / \mathrm{mL})$ than ASD $(437.2 \pm 174.2 \mathrm{ng} / \mathrm{mL})$, and a greater $C_{\max } 2(985.8 \pm 366.6 \mathrm{ng} / \mathrm{mL})$ than ASD $(180.5 \pm 75.1 \mathrm{ng} / \mathrm{mL})$ and APC $(549.7 \pm 113.5 \mathrm{ng} / \mathrm{mL})$. Compared with ASD, $T_{\max } 1$ and $T_{\max } 2$ were both remarkably shortened by APC-SNEDDS. The oral bioavailability in rats was enhanced significantly to $183.8 \%$ and $431.8 \%$ by APC and APC-SNEDDS, respectively.

Conclusion: These results indicated that APC-SNEDDS was a promising drug delivery system to enhance the oral bioavailability of ASD.

Keywords: Akebia saponin D, phospholipid complex, self-nanoemulsifying drug delivery systems, oral bioavailability

\section{Introduction}

Akebia saponin D (ASD; Figure 1) is a triterpenoid saponin isolated from the rhizome of Dipsacus asper Wall. It has been reported to possess anti-osteoporotic, hepatoprotective, neuroprotective, and cardioprotective effects. ${ }^{1-4}$

However, ASD is poorly absorbed when administrated orally. The oral bioavailability of ASD in rats is only $0.13 \% .{ }^{5}$ The poor oral absorption of ASD could mainly result from 


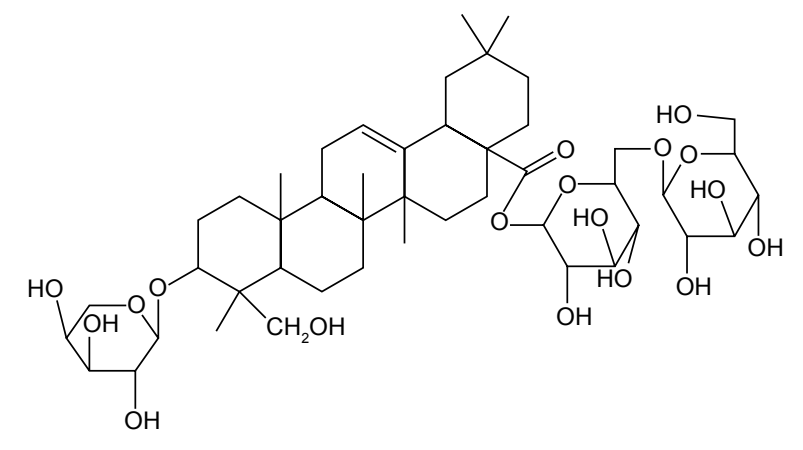

Figure I The structure of ASD.

Abbreviation: ASD, Akebia saponin D.

the low intestinal permeability, ${ }^{6}$ efflux mediated by MRP, ${ }^{6}$ metabolism in the intestine, ${ }^{7}$ excretion from the bile, ${ }^{8}$ and elimination in the liver. Therefore, it is necessary to develop a dosage form to overcome these absorbing barriers.

Some oral drug delivery systems have been employed to improve oral absorption of hydrophilic saponins, including water-in-oil (W/O) microemulsion ${ }^{9}$ and oils. ${ }^{10,11}$ It seemed that a W/O microemulsion was suitable for ASD. However, phase inversion happened frequently in vivo when the $\mathrm{W} / \mathrm{O}$ microemulsion formulation was diluted with gastrointestinal fluid, leading to the leakage of compounds into the aqueous media and loss of absorption enhancement. ${ }^{12}$ In oils, some hydrophobic esters and their hydrolysis products by pancreatic lipase could significantly promote intestinal absorption of poorly absorbed drugs. ${ }^{10,11,13}$ Nevertheless, emulsions would form when these hydrophobic esters are diluted with gastrointestinal fluid, leading to a longer release time and a delayed absorption of drugs in vivo, ${ }^{10,11}$ which is undesired for any drug.

Until now, some phytochemicals have been loaded into oral nanoparticles to improve their aqueous solubility, permeation, stability, circulation time, target specificity, and bioavailability. ${ }^{14,15}$ The common biodegradable and biocompatible nanoparticles include nanoemulsions, nanoliposomes, micelles, lipid nanocarriers, and poly(lacticco-glycolic acid) nanoparticles. ${ }^{16-20}$ Self-nanoemulsifying drug delivery system (SNEDDS) is an anhydrous homogenous liquid mixture consisting of oil, surfactant, cosurfactant, and drug, which spontaneously forms oil-in-water nanoemulsion of $<200 \mathrm{~nm}$ in size upon dilution with water under gentle stirring. ${ }^{21}$ SNEDDS improves drug delivery by improving permeability or transport of poorly permeable drugs, attenuating the activity of intestinal efflux transporters, preventing degradation of drugs in physiological milieu, and facilitating absorption of drugs via intestinal lymphatic pathway. ${ }^{21}$ Due to these advantages, SNEDDS was applied to improve oral absorption of ASD in this study.
Until now, some pharmaceutical excipients, which are commonly used in pharmaceutical formulations, have been identified as potential inhibitors of MRP. For example, Cremophor ${ }^{\circledR}$ RH 40 (Polyoxyl 40 hydrogenated castor oil) and Cremophor ${ }^{\circledR}$ EL (Polyoxyl 35 castor oil) have been proved to possess inhibitory effects on MRP. ${ }^{22}$ Polyoxyl 40 hydrogenated castor oil and Polyoxyl 35 castor oil are nonionic surfactants which are considered as less toxic than other types of surfactants and less influenced by ionic strength and $\mathrm{pH}$ change. Therefore, these two excipients were considered for incorporation in SNEDDS to increase the intestinal absorption of ASD.

SNEDDS has been widely employed as a delivery system for poorly water-soluble drugs. ${ }^{23-26}$ As a hydrophilic compound, ASD cannot be directly entrapped into SNEDDS without any change. Previously, a phospholipid-based strategy was established to develop SNEDDS for several hydrophilic drugs (matrine and insulin), in which phospholipid complexes were formulated to significantly enhance the liposolubility of water-soluble drugs and drastically facilitate their incorporation into SNEDDS. ${ }^{12,27}$ Oral absorption of matrine and insulin was significantly improved by this special formulation. In this study, a phospholipid complex was employed to improve the liposolubility of ASD and facilitate the incorporation of ASD into SNEDDS.

Therefore, the objective of the present study was to develop a novel SNEDDS based on the phospholipid complex technique to enhance the oral bioavailability of ASD. Hopefully, this study could provide not only a promising oral formulation of ASD for its clinical application but also references for further study of other hydrophilic saponins.

\section{Materials and methods Materials}

ASD (95.23\%, high-performance liquid chromatography purity) was a pilot product prepared by our laboratory. Its purity was calibrated by the standard substance purchased from the National Institutes for Food and Drug Control (Beijing, People's Republic of China). Phospholipid (91.4\% phosphatidylcholine) was purchased from Beijing Yuan Hua Mei Lecithin Sci-Tech Co., Ltd. (Beijing, People's Republic of China). Labrafac Lipophile WL 1349, Labrafil M 1944 CS, Peceol (Glyceryl monooleate [type 40]), Maisine 35-1, Capryol 90, and Transcutol HP (Diethylene glycol monoethyl ether) were kindly supplied by Gattefossé (Saint-Priest Cedex, France). Olive oil, oleic acid, ethyl oleate, polyethylene glycol 400, and 1,2-propanediol were purchased from Nanjing Chemical Reagent Co., LTD. (Nanjing, People's Republic of China). Polyoxyl 40 hydrogenated castor oil and Polyoxyl 35 castor oil were donated by BASF 
(Ludwigshafen, Germany). Diazepam (purity $\geq 98 \%$ ) was purchased from Aladdin Industrial Corporation (Shanghai, People's Republic of China). All the other chemicals were of analytical or chromatography grade.

\section{Preparation of ASD-phospholipid complex}

The ASD-phospholipid complex (APC) was prepared with ASD and phospholipids at a molar ratio of 1:3. Weighed amount of ASD (0.6500 g) and phospholipids (1.5750 g) was put in a $100 \mathrm{~mL}$ conical flask, and $50 \mathrm{~mL}$ of ethanol was added. The mixture was stirred with a magnetic agitator (Wanfeng Instrument Co., Ltd., Jintan, People's Republic of China) at $50^{\circ} \mathrm{C}$ for 2 hours. The resultant clear solution was concentrated to dry under nitrogen at room temperature. Later, the residue was dried under vacuum for 36 hours to obtain APC, and APC was transferred into a desiccator and stored at room temperature.

\section{Characterization of APC}

The interactions between ASD and phospholipids were studied using Fourier transform infrared (FT-IR) spectroscopy and differential scanning calorimetry (DSC). The FT-IR spectra of ASD, phospholipid, APC, and physical mixture of $\mathrm{ASD}$ and phospholipids were recorded in the range of $4,000-400 \mathrm{~cm}^{-1}$ with a resolution of $4 \mathrm{~cm}^{-1}$ using a Bruker tensor 27 FT-IR spectrometer (Bruker Corporation, Billerica, MA, USA). DSC analyses were carried out on a Netzsch DSC 204 F1 phoenix differential scanning calorimeter (Netzsch, Selb, Germany). The samples were heated from $40^{\circ} \mathrm{C}$ to $350^{\circ} \mathrm{C}$ at a heating rate of $10^{\circ} \mathrm{C} / \mathrm{min}$ under a nitrogen purge gas flow of $20 \mathrm{~mL} / \mathrm{min}$.

The morphology and surface characteristics of ASD and APC were examined by a Hitachi S-3000N scanning electron microscope (Hitachi Ltd., Tokyo, Japan) at an accelerated voltage of $20 \mathrm{kV}$.

\section{Determination of ASD content in APC}

The content of ASD in APC was determined by HPLC method. The analysis was performed on an Agilent 1260 HPLC system equipped with an ODS-C18 column $(150 \times 4.6 \mathrm{~mm}, 5 \mu \mathrm{m})$ (Agilent Technologies, Santa Clara, CA, USA). The mobile phase was acetonitrile:water $(35: 65, \mathrm{v} / \mathrm{v})$ at a flow rate of $1 \mathrm{~mL} / \mathrm{min}$. Column temperature was maintained at $30^{\circ} \mathrm{C}$, and detection wavelength was set at $212 \mathrm{~nm}$.

\section{Solubility studies}

Solubility studies in water and $n$-octanol were conducted to verify whether the liposolubility of ASD was improved after formation of APC. Briefly, excess amount of ASD,
APC, and physical mixture of ASD and phospholipids was added to $2 \mathrm{~mL}$ water or $n$-octanol in sealed penicillin bottles at $37^{\circ} \mathrm{C}$, respectively. The samples were shaken for 24 hours and then centrifuged at $10,012 \times g$ for 10 minutes. Later, the supernatants were collected and diluted with methanol. The concentration of ASD was assayed by the aforementioned HPLC method.

Solubility studies of APC in eight kinds of oils, two types of nonionic surfactants, and three types of cosurfactants were carried out to optimize proper excipients with maximum solubilization, and to obtain optimum drug loading. Briefly, an excess amount of APC was introduced into $1 \mathrm{~mL}$ of each excipient, and the mixtures were kept in sealed penicillin bottles. The samples were shaken for 24 hours at $37^{\circ} \mathrm{C}$ and then centrifuged at $10,012 \times g$ for 10 minutes. The concentration of ASD in supernatant was determined by the aforementioned HPLC method.

\section{Selection of surfactant}

The emulsification efficiency was investigated to select the proper surfactant between Polyoxyl 40 hydrogenated castor oil and Polyoxyl 35 castor oil. At a certain weight of oil (Glyceryl monooleate [type 40]), each of the surfactants was mixed with selected cosurfactant (Diethylene glycol monoethyl ether) at ratios of $4: 1,3: 1$, and $2: 1$. The experimental arrangement of formulations is shown in Table 1. Each formulation was dispersed into the distilled water at a ratio of 1:100 (w/w) with gentle magnetic stirring. The spontaneous self-emulsifying properties, appearance, and dispersibility of each formulation were visually assessed based on the five grading systems ${ }^{28}$ presented in Table 2 .

\section{Construction of pseudoternary phase diagram}

The pseudoternary phase diagram was used to identify the self-nanoemulsifying region of the selected system with

Table I Experimental arrangement of formulations

\begin{tabular}{|c|c|c|c|c|c|c|}
\hline \multirow[t]{2}{*}{ Excipient } & \multicolumn{6}{|c|}{ Formulation $(\%, w / w)$} \\
\hline & $\mathrm{I}$ & 2 & 3 & 4 & 5 & 6 \\
\hline $\begin{array}{l}\text { Peceol (Glyceryl } \\
\text { monooleate [type 40]) }\end{array}$ & 20 & 20 & 20 & 20 & 20 & 20 \\
\hline $\begin{array}{l}\text { Cremophor }^{\circledR} \text { EL (Polyoxyl } \\
35 \text { castor oil) }\end{array}$ & 52 & 58.5 & 62.4 & - & - & - \\
\hline $\begin{array}{l}\text { Cremophor }^{\otimes} \text { RH } 40 \\
\text { (Polyoxyl } 40 \text { hydrogenated } \\
\text { castor oil) }\end{array}$ & - & - & - & 52 & 58.5 & 62.4 \\
\hline $\begin{array}{l}\text { Transcutol HP (Diethylene } \\
\text { glycol monoethyl ether) }\end{array}$ & 26 & 19.5 & 15.6 & 26 & 19.5 & 15.6 \\
\hline Grade & I & I & I & II & II & II \\
\hline
\end{tabular}


Table 2 Visual assessment of efficiency of self-emulsification

\begin{tabular}{lll}
\hline Grade & Dispersibility and appearance & $\begin{array}{l}\text { Time of self- } \\
\text { emulsification } \\
\text { (minutes) }\end{array}$ \\
\hline I & $\begin{array}{l}\text { Rapidly forming nanoemulsion which is clear } \\
\text { or slightly bluish in appearance }\end{array}$ & $<$ I \\
II $\quad \begin{array}{l}\text { Rapidly forming, slightly less clear emulsion } \\
\text { which has a bluish white appearance }\end{array}$ & $<2$ \\
III $\quad \begin{array}{l}\text { Bright white emulsion (similar to milk in } \\
\text { appearance) }\end{array}$ & $<3$ \\
IV $\quad \begin{array}{l}\text { Dull, grayish white emulsion with a slight } \\
\text { oily appearance that is slow to emulsify } \\
\text { Exhibits poor or minimal emulsification with } \\
\text { large oil droplets present on the surface }\end{array}$ & $>3$ \\
V &
\end{tabular}

different drug loading. On the basis of studies conducted, Glyceryl monooleate (type 40), Polyoxyl 35 castor oil, and Diethylene glycol monoethyl ether were selected as the oil, surfactant, and cosurfactant, respectively. A series of formulations with varying concentrations of Glyceryl monooleate (type 40$)(0 \%-20 \%$, w/w), Polyoxyl 35 castor oil $(20 \%-50 \%$, $\mathrm{w} / \mathrm{w})$, Diethylene glycol monoethyl ether $(20 \%-50 \%$, w/w), and APC $(0 \%-15 \%$, w/w) were prepared. Each sample was sonicated until clear liquid mixture appeared and then added dropwise into distilled water at a ratio of 1:100 (w/w) with gentle magnetic stirring. Through investigating the tendency to emulsify and observing the dispersibility and appearance, it was easy to differentiate between the nanoemulsion and the simple emulsion. The self-nanoemulsifying regions were plotted on pseudoternary phase diagrams.

\section{Characterization of APC-SNEDDS}

The droplet size (number-weighted) and zeta potential of APC-SNEDDS diluted with distilled water $(1: 100, w / w)$ were measured by dynamic light scattering using a BI-90 Plus particle size analyzer (Brookhaven Instruments Corporation, Holtsville, NY, USA). These parameters were repeatedly measured for three times.

The morphology of APC-SNEDDS was observed by a Hitachi H-600 transmission electron microscope (Hitachi Ltd.). Briefly, APC-SNEDDS was diluted with distilled water at a ratio of 1:100 (w/w), and a drop of sample was placed on a copper grid. After removal of excess liquid, the sample was negatively stained by $2 \%$ phosphomolybdic acid and then subjected to observation under a transmission electron microscope.

\section{APC-SNEDDS stability analysis}

The influences of $\mathrm{pH}$ and volume of the diluents on the droplet size of APC-SNEDDS were evaluated by diluting with deionized water, $\mathrm{pH} 1.2$ simulated gastric fluid $(0.1 \mathrm{M}$ $\mathrm{HCl}$ ), and $\mathrm{pH} 6.8$ simulated intestinal fluid (phosphatebuffered saline) to 50-, 100-, and 1,000-fold, respectively. The droplet size was measured using a BI-90 Plus particle size analyzer (Brookhaven Instruments Corporation) after 10 minutes of dilution.

The thermodynamic stability of APC-SNEDDS was evaluated using a heating-cooling test at $40^{\circ} \mathrm{C}$ and $-4^{\circ} \mathrm{C}$ for 48 hours and six refrigerator cycles. The formulation was assessed for the changes in particle size, cracking, creaming, and phase separation.

All these experiments were repeated for three times.

\section{Pharmacokinetic studies in rats}

The animal studies were approved by the Animal Ethics Committee of China Pharmaceutical University (Nanjing, People's Republic of China). Sprague Dawley rats (body weight 200-220 g, n=18) were obtained from the Zhejiang Animal Breeding Center (Hangzhou, People's Republic of China). All rats were divided randomly into three groups (half male and half female in each group) and fasted for 12 hours but granted free access to water prior to experiment. ASD, APC, and APC-SNEDDS at a dose equivalent to $90 \mathrm{mg} / \mathrm{kg}$ of ASD were dispersed in distilled water and orally administrated to the three groups of rats $(n=6)$, respectively.

Blood samples $(250 \mu \mathrm{L})$ were collected from the eye ground veins pre-dose and at the predetermined time points $(0.167,0.333,0.5,1,3,5,7,9,11,14,18,24,30$, and 36 hours post-dosing). The plasma samples were collected after centrifugation $\left(1,112 \times \mathrm{g}, 10\right.$ minutes) and stored at $-20^{\circ} \mathrm{C}$ until analysis.

An aliquot of $100 \mu \mathrm{L}$ rat plasma was mixed with $280 \mu \mathrm{L}$ methanol and $20 \mu \mathrm{L}$ internal standard (IS; diazepam, $700 \mathrm{ng} / \mathrm{mL}$ ). The mixture was vortex-mixed for 5 minutes and then centrifuged at $10,012 \times g$ for 10 minutes. The supernatant $(300 \mu \mathrm{L})$ was transferred to a centrifuge tube and evaporated to dryness. The obtained residue was reconstituted in $150 \mu \mathrm{L}$ methanol, and an aliquot of $8 \mu \mathrm{L}$ was used for HPLC-tandem mass spectrometry (MS/MS) analysis.

The HPLC-MS/MS analysis was carried out on an Agilent 1260 liquid chromatograph (Agilent Technologies) with an Agilent 6420 triple quadrupole mass spectrometer (Agilent Technologies) equipped with an electrospray source (model G1956B). Chromatographic separation was performed on a Hedera ODS-2 column $(2.1 \times 150 \mathrm{~mm}, 5 \mu \mathrm{m})$ (Hanbon Science and Technology, Huaian, People's Republic of China) with a security Guard-C18 column $(4.6 \times 12.5 \mathrm{~mm}$, $5 \mu \mathrm{m}$ ) (Agilent Technologies). The mobile phase, consisting 
of methanol-10 $\mathrm{mM}$ ammonium acetate buffer solution containing $0.05 \%$ acetic acid $(76: 24, \mathrm{v} / \mathrm{v})$, was delivered at a flow rate of $0.39 \mathrm{~mL} / \mathrm{min}$. The column temperature was maintained at $30^{\circ} \mathrm{C}$. The electrospray ionization-MS/ MS operation parameters were set as follows: positive ion electrospray; drying gas $\left(\mathrm{N}_{2}\right)$ temperature, $350^{\circ} \mathrm{C}$; drying gas $\left(\mathrm{N}_{2}\right)$ flow rate, $8 \mathrm{~L} / \mathrm{min}$; capillary voltage, $4.0 \mathrm{kV}$; nebulizer pressure, 15 psig; fragmentor voltage, $156 \mathrm{~V}$ for ASD and $140 \mathrm{~V}$ for the IS; and collision energy, $20 \mathrm{eV}$ for ASD and $30 \mathrm{eV}$ for the IS. Multiple-reaction monitoring used the transitions of $m / z \quad 946.4 \rightarrow 455.3$ for ASD and $m / z 285.1 \rightarrow 192.9$ for the IS.

The pharmacokinetic parameters were analyzed with a non-compartmental model (DAS, Version 2.1.1; Chinese Pharmacological Association, Shanghai, People's Republic of China). The relative bioavailability $(F)$ was calculated by the following equation:

$$
F(\%)=\mathrm{AUC}_{\text {test }} / \mathrm{AUC}_{\mathrm{ASD}} \times 100
$$

where AUC is the area under the plasma concentration-time curve from 0 to 36 hours.

\section{Statistical analysis}

Statistical analyses were performed using Student's $t$-test, and a value of $P<0.05$ was considered to be significantly different.

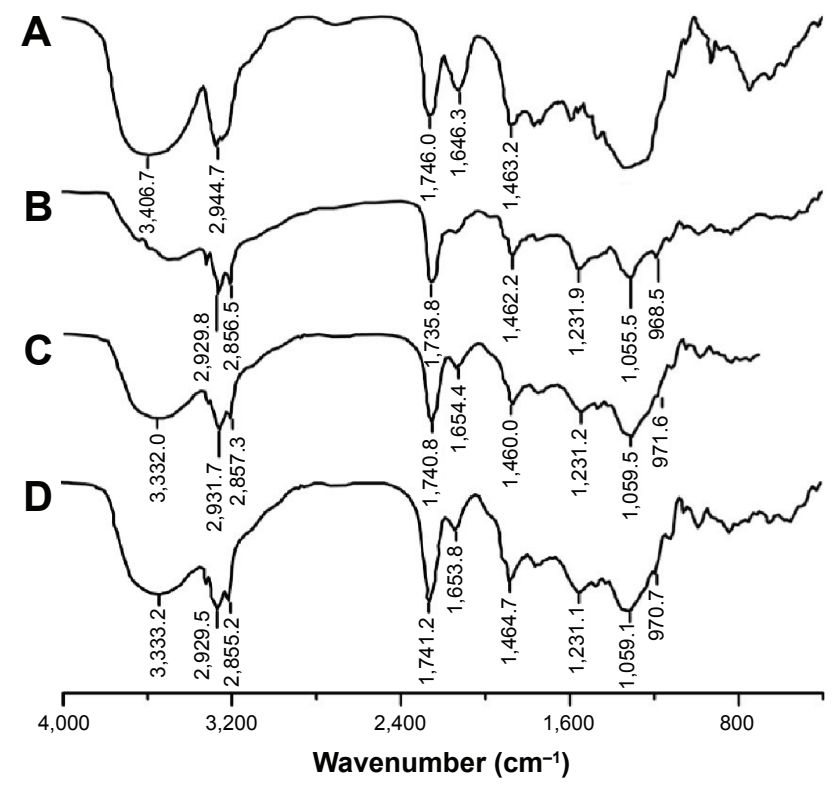

Figure 2 Infrared spectra.

Notes: (A) ASD. (B) Phospholipids. (C) Physical mixture of ASD and phospholipids. (D) APC.

Abbreviations: ASD, Akebia saponin D; APC, Akebia saponin D-phospholipid complex.

\section{Results}

\section{Characterization of APC}

The interactions between ASD and phospholipids were studied using FT-IR spectroscopy (Figure 2A-D) and DSC (Figure 3A-D). There were some differences between the ASD FT-IR spectrum (Figure 2A) and APC FT-IR spectrum (Figure 2D). The characteristic absorption peak of ASD at 3,406.7 $\mathrm{cm}^{-1}$ (for O-H stretch vibration) shifted to $3,333.2 \mathrm{~cm}^{-1}$ in the spectrum of APC, and the characteristic absorption peak of ASD at 2,944.7 $\mathrm{cm}^{-1}$ (for $\mathrm{C}-\mathrm{H}$ stretch vibration) could not be found in the spectrum of APC, indicating interactions between ASD and phospholipids. Moreover, no new peaks were observed in the spectra of APC and physical mixture (Figure 2C).

DSC is a reliable method to explore the possible interactions between drug and excipients. ${ }^{27}$ In DSC, a possible interaction can be concluded by appearance of new peak, elimination of endothermic peak, changes in peak shape and its onset, melting point, and relative peak area or enthalpy. ${ }^{27}$ Thermogram of ASD (Figure 3A) exhibited two endothermic peaks with onset temperature at $59.4^{\circ} \mathrm{C}$ and $198.8^{\circ} \mathrm{C}$, respectively. The second peak $\left(198.8^{\circ} \mathrm{C}\right)$ might have been caused by melting of ASD. Thermogram of phospholipids (Figure 3B) showed two endothermic peaks $\left(50.2^{\circ} \mathrm{C}\right.$ and $167.7^{\circ} \mathrm{C}$ ) and one exothermic peak $\left(310.4^{\circ} \mathrm{C}\right)$. The physical mixture of ASD and phospholipids (Figure $3 \mathrm{C}$ ) showed three endothermic peaks $\left(49^{\circ} \mathrm{C}, 164.8^{\circ} \mathrm{C}\right.$, and $\left.266.6^{\circ} \mathrm{C}\right)$ and one exothermic peak $\left(315.4^{\circ} \mathrm{C}\right)$. When the thermograms of ASD and phospholipids were compared, we noted that the endothermic peak $\left(198.8^{\circ} \mathrm{C}\right)$ caused by melting of ASD was missing, and found a new endothermic peak $\left(266.6^{\circ} \mathrm{C}\right)$ in the thermogram of mixture. This might have been due to the speculation that when temperature increased, phospholipids melted and then ASD dissolved in the phospholipids partly forming the complex. The formation of phospholipid complex changed the melting temperature of ASD from $198.8^{\circ} \mathrm{C}$ to $266.6^{\circ} \mathrm{C}$. The thermogram of APC (Figure 3D) was in accordance with the thermogram of physical mixture.

The morphologies of ASD and APC under scanning electron microscope are shown in Figure 4. ASD (Figure 4A) appeared as an irregular granule with edges and corners. APC (Figure 4B) did not show the appearance of ASD but appeared to be spherical with a smooth surface.

The content of ASD in the phospholipid complex determined by HPLC was $26.8 \% \pm 0.52 \%$. The value was concordant with the reactant ratio of ASD and phospholipids. 


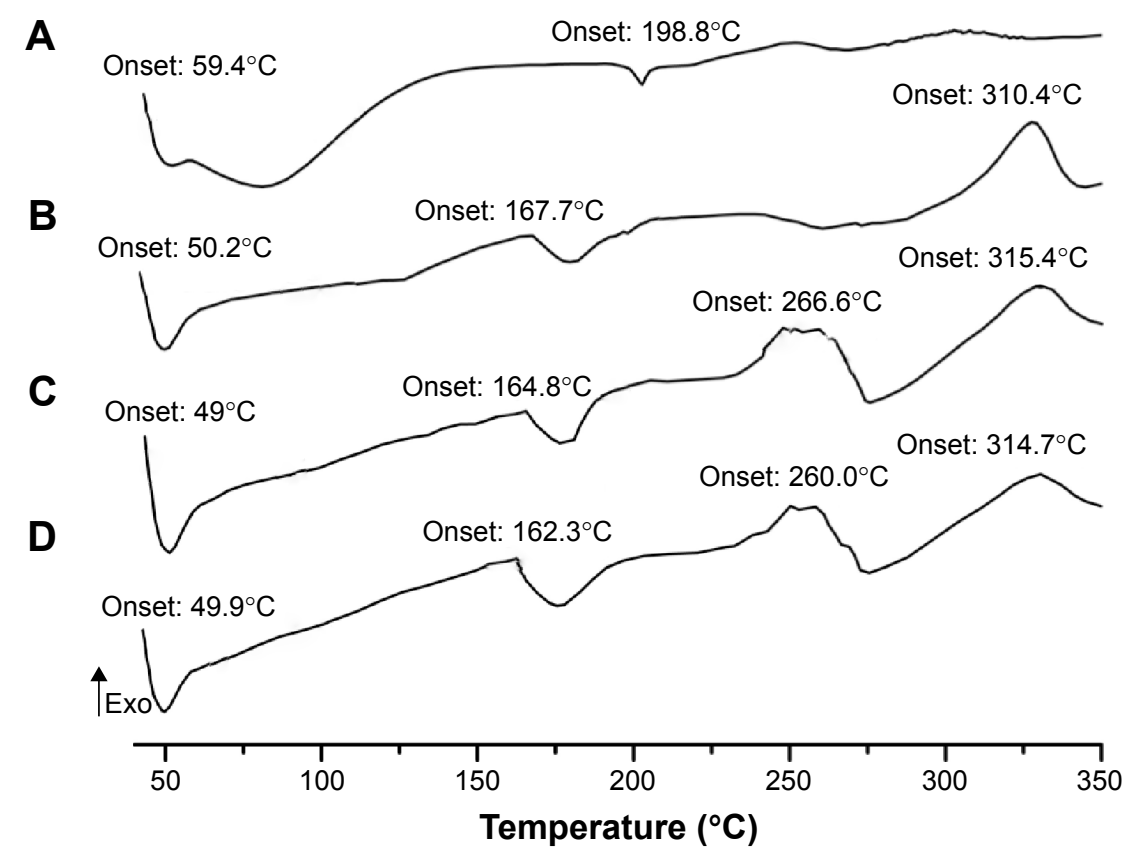

Figure 3 DSC thermograms.

Notes: (A) ASD. (B) Phospholipids. (C) Physical mixture of ASD and phospholipids. (D) APC.

Abbreviations: DSC, differential scanning calorimetry; ASD, Akebia saponin D; APC, Akebia saponin D-phospholipid complex; Exo, exothermic.

\section{Solubility studies}

The change of liposolubility was studied by the solubility tests in water and $n$-octanol. As shown in Table 3, APC exhibited much higher solubility in $n$-octanol and water compared with ASD and physical mixture. The results indicated that the hydrophilicity and liposolubility of ASD were both significantly enhanced after the formation of APC.

In order to obtain a large drug loading, solubility studies in various carriers were carried out. Figure 5A shows that Glyceryl monooleate (type 40) had the maximum drug solubility $(6.53 \pm 0.22 \mathrm{mg} / \mathrm{mL})$ among the oils tested. Glyceryl monooleate (type 40), a readily dispersible and lymphotropic solubilizing agent composed mainly of a mixture of monoand diglycerides of oleic acid, had been used in the selfemulsifying drug delivery system by other researchers. ${ }^{29,30}$ Moreover, Diethylene glycol monoethyl ether showed the largest solubility $(236.29 \pm 21 \mathrm{mg} / \mathrm{mL})$ as compared with the other cosurfactants (Figure 5B). Diethylene glycol monoethyl ether, a highly purified diethylene glycol monoethyl ether, was often employed in the SNEDDS formulation as a coemulsifier or solubilizer for actives. ${ }^{31}$ Therefore, Glyceryl monooleate (type 40) and Diethylene glycol monoethyl
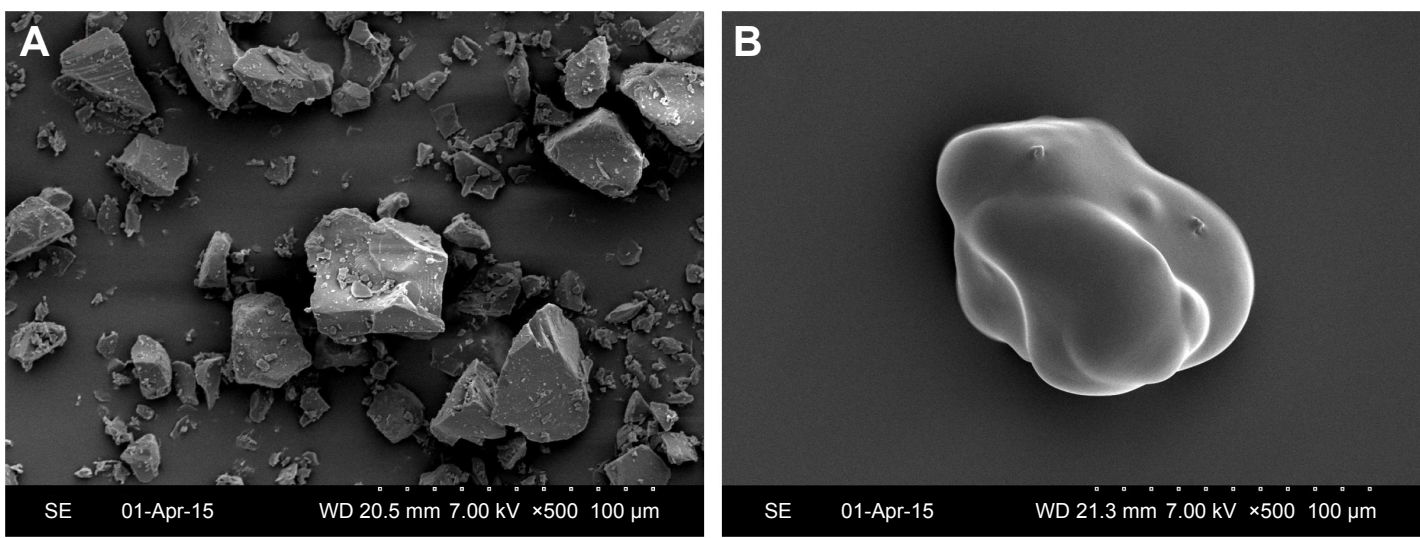

Figure 4 Scanning electron micrographs.

Notes: (A) ASD ( $\times 500$ magnification). (B) APC $(\times 500$ magnification).

Abbreviations: ASD, Akebia saponin D; APC, Akebia saponin D-phospholipid complex. 
Table 3 Solubility of ASD, physical mixture, and APC in water and $n$-octanol $(n=3)$

\begin{tabular}{lll}
\hline Sample & $\begin{array}{l}\text { Solubility in } \\
\text { water }(\mathrm{mg} / \mathrm{mL})\end{array}$ & $\begin{array}{l}\text { Solubility in } \\
\text { n-octanol }(\mathrm{mg} / \mathrm{mL})\end{array}$ \\
\hline ASD & $10.70 \pm 0.51$ & $2.38 \pm 0.12$ \\
Physical mixture & $4.36 \pm 0.20$ & $2.84 \pm 0.36$ \\
APC & $20.96 \pm 1.21$ & $29.58 \pm 1.69$ \\
\hline
\end{tabular}

Abbreviations: ASD, Akebia saponin D; APC, Akebia saponin D-phospholipid complex.

ether were selected as the oil and cosurfactant, respectively. Both nonionic surfactants (Polyoxyl 40 hydrogenated castor oil and Polyoxyl 35 castor oil) had very less solubility $(<0.6 \mathrm{mg} / \mathrm{mL})$, so further study is needed to select the proper surfactant.

\section{Selection of surfactant}

Emulsification efficiency is more important than the ability to solubilize the drug during the selection of surfactants for using in an SNEDDS formulation. ${ }^{26}$ Grade of different weight ratios of surfactant/cosurfactant is shown in Table 1. The results clearly indicated that Polyoxyl 35 castor oil was more effective in making a grade I nanoemulsion, and it was preliminarily chosen as the surfactant in the system.

\section{Development of APC-SNEDDS}

The pseudoternary phase diagram was widely used to optimize the formulation during the development of SNEDDS. ${ }^{23,24}$ The self-nanoemulsifying regions of the selected SNEDDS with varying drug loading (from $0 \%$ to $5 \%$ ) were present on the pseudoternary phase diagrams. Through observation, the self-nanoemulsifying region was found to decrease when the drug loading increased. The droplet size of the SNEDDS determined the bioavailability and stability of the formulated drugs, ${ }^{32,33}$ so it was adopted as a key criterion to select the proper formulation. Emulsion with a higher zeta potential will be more stable, ${ }^{21}$ so zeta potential was another important selection criterion. Table 4 shows that particle size increased and zeta potential decreased with the increase in drug loading. Although larger drug loading was preferred, the formulation with 5\% drug loading had the smallest self-nanoemulsifying region, lowest zeta potential, and largest particle size, indicating an unstable drug delivery system. To obtain a good balance between drug loading and efficient emulsification, the formulation composed of Glyceryl monooleate (type 40), Polyoxyl 35 castor oil, Diethylene glycol monoethyl ether, and APC (1:4.5:4.5:1.74, w/w/w/w) with a drug loading of $4 \%(w / w)$ was selected as the best one of its kind. The pseudoternary phase diagram of the selected SNEDDS is shown in Figure 6.

\section{Characterization of APC-SNEDDS}

The prepared APC-SNEDDS exhibited a mean particle size of $148.0 \pm 2.7 \mathrm{~nm}$ and a zeta potential of $-13.7 \pm 0.92 \mathrm{mV}$ as shown in Table 4. As shown in Figure 7, APC-SNEDDS had a uniform and spherical morphology with a narrow size distribution.

\section{APC-SNEDDS stability}

Nanoemulsions, colloidal dispersions of nanosized oil droplets in aqueous mediums, are thermodynamically unstable and kinetically stable systems. ${ }^{34}$ It is necessary to evaluate their robustness to dilution and thermodynamic stability. In this study, APC-SNEDDS showed no significant changes of the droplet size in different $\mathrm{pH}$ diluents (Table 5). Additionally, heating-cooling cycles also had no significant

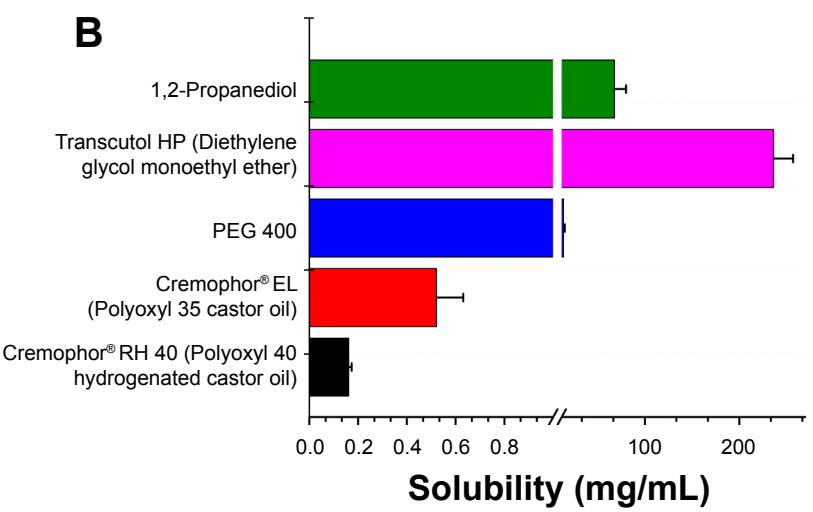

Figure 5 Solubility of APC in various carriers.

Notes: (A) Oils. (B) Surfactant and cosurfactant ( $n=3)$. PEG 400, Diethylene glycol monoethyl ether, and I,2-propanediol were tested for surfactant. Polyoxyl 40 hydrogenated castor oil and Polyoxyl 35 castor oil were tested for cosurfactant.

Abbreviations: APC, Akebia saponin D-phospholipid complex; PEG 400, polyethylene glycol 400. 
Table 4 Droplet size, polydispersity index, and zeta potential of SNEDDS formulations with different drug loading after dilution with distilled water at a ratio of $1: 100$

\begin{tabular}{lllll}
\hline System & $\begin{array}{l}\text { Drug } \\
\text { loading (\%) }\end{array}$ & $\begin{array}{l}\text { Particle size, } \\
\text { mean } \pm \text { SD (nm) }\end{array}$ & $\begin{array}{l}\text { Percent polydispersity, } \\
\text { mean } \pm \text { SD (\%) }\end{array}$ & $\begin{array}{l}\text { Zeta potential, } \\
\text { mean } \pm \text { SD (mV) }\end{array}$ \\
\hline Peceol (Glyceryl monooleate [type 40])/ & 0 & $13.6 \pm 0.4$ & 3.19 & $-28.5 \pm 1.3$ \\
Cremophor $^{\circledR}$ EL (Polyoxyl 35 castor oil)/ & 1 & $38.2 \pm 3.2$ & 1.47 & $-26.2 \pm 1.45$ \\
Transcutol HP (Diethylene glycol monoethyl & 2 & $84.7 \pm 1.1$ & 0.576 & $-22.9 \pm 1.21$ \\
ether)/APC & 3 & $120.6 \pm 0.6$ & 0.436 & $-18.6 \pm 0.85$ \\
& 4 & $148.0 \pm 2.7$ & 0.378 & $-13.7 \pm 0.92$ \\
& 5 & $256.0 \pm 3.1$ & 0.273 & $-4.9 \pm 0.57$ \\
\hline
\end{tabular}

Notes: ${ }^{a}$ Reported as number-weighted size. ${ }^{b}$ Calculated by the following equation: (polydispersity/[mean hydrodynamic radius]) $\times 100 \%$. Glyceryl monooleate (type 40 )/ Polyoxyl 35 castor oil/Diethylene glycol monoethyl ether =l:4.5:4.5 (w/w/w); $n=3$.

Abbreviations: SNEDDS, self-nanoemulsifying drug delivery system; SD, standard deviation; APC, Akebia saponin D-phospholipid complex.

effect on the droplet size (Table 5) and physical appearance of APC-SNEDDS.

\section{Pharmacokinetic results}

The pharmacokinetic data were processed using a non-compartmental model. The plasma concentration-time curves obtained after oral administration are shown in Figure 8. The main pharmacokinetic parameters are listed in Table 6 .

Compared with ASD group, $T_{\max } 1$ was found to be significantly shortened from $2.0 \pm 1.1$ to $0.195 \pm 0.068$ and $0.195 \pm 0.068$ hours for the APC and APC-SNEDDS groups, respectively. Meanwhile, $C_{\max } 2$ significantly increased from $180.5 \pm 75.1$ to $549.7 \pm 113.5$ and $985.8 \pm 366.6 \mathrm{ng} / \mathrm{mL}$ for the APC and APC-SNEDDS groups, respectively. APC-SNEDDS group's $C_{\max } 1$ was significantly higher and

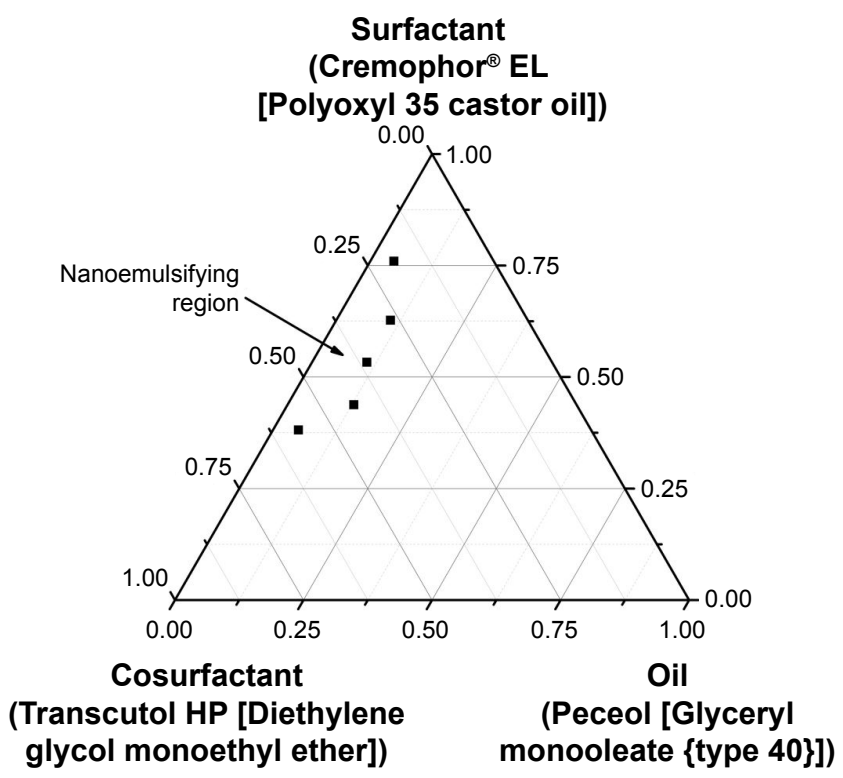

Figure 6 Pseudoternary phase diagram of the SNEDDS formulation composed of Glyceryl monooleate (type 40), Polyoxyl 35 castor oil, Diethylene glycol monoethyl ether, and APC with a drug loading of $4 \%$.

Abbreviations: SNEDDS, self-nanoemulsifying drug delivery system; APC, Akebia saponin D-phospholipid complex.
$T_{\max } 2$ was significantly shorter compared with ASD group. The relative bioavailability of APC and APC-SNEDDS was $183.8 \%$ and $431.8 \%$ with ASD group as control group, respectively.

Compared with APC group, $C_{\max } 1$ and $C_{\max } 2$ of APCSNEDDS group were found to be significantly improved. $\mathrm{AUC}_{0-36 \mathrm{~h}}$ increased from 5,551.1 $\pm 1,357.4$ to $13,038.4 \pm$ $5,121.7 \mathrm{ng} \cdot \mathrm{h} / \mathrm{mL}$ with statistical difference. The results indicated that the oral absorption was further improved by the formation of SNEDDS compared with phospholipid complex.

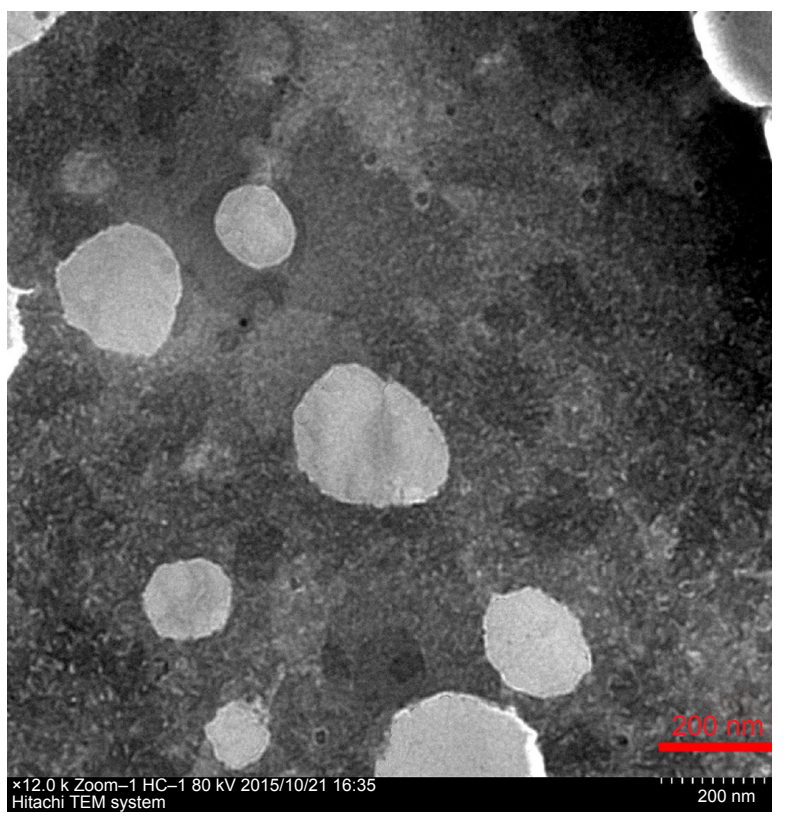

Figure 7 Transmission electron microscope image of APC-SNEDDS formulation $(\times 12,000$ magnification).

Note: The SNEDDS was composed of Peceol (Glyceryl monooleate [type 40]), Cremophor ${ }^{\circledR}$ EL (Polyoxyl 35 castor oil), Transcutol HP (Diethylene glycol monoethyl ether), and APC with a drug loading of $4 \%$.

Abbreviations: APC, Akebia saponin D-phospholipid complex; SNEDDS, selfnanoemulsifying drug delivery system. 
Table 5 Effects of aqueous phase $\mathrm{pH}$, dilution factor, and heatingcooling cycles on droplet size of APC-SNEDDS (mean \pm SD, $n=3$ )

\begin{tabular}{lllll}
\hline $\begin{array}{l}\text { Dilution } \\
\text { factor }\end{array}$ & $\begin{array}{l}\text { Water } \\
(\mathbf{n m})\end{array}$ & $\begin{array}{l}\mathrm{pH} \mathrm{I.2} \\
(\mathbf{n m})\end{array}$ & $\begin{array}{l}\mathrm{pH} \mathrm{6.8} \\
(\mathbf{n m})\end{array}$ & $\begin{array}{l}\text { After heating- } \\
\text { cooling test }\end{array}$ \\
\hline 50 & $150.1 \pm 3.8$ & $149.6 \pm 3.3$ & $147.1 \pm 5.1$ & - \\
100 & $148.0 \pm 2.7$ & $148.9 \pm 4.5$ & $149.7 \pm 4.5$ & $148.3 \pm 5.2$ \\
1,000 & $147.3 \pm 4.1$ & $151.2 \pm 4.7$ & $148.3 \pm 4.2$ & - \\
\hline
\end{tabular}

Abbreviations: APC, Akebia saponin D-phospholipid complex; SNEDDS, selfnanoemulsifying drug delivery system; SD, standard deviation.

In conclusion, the oral absorption of ASD was profoundly increased by APC-SNEDDS with an outstanding $F$ of $431.8 \%$.

\section{Discussion}

Many naturally occurring hydrophilic saponins exert various pharmacological effects but with unsatisfied oral absorption. ${ }^{35,36}$ Poor bioavailability has been the major challenge in developing hydrophilic saponins as clinically useful drugs. In this study, an SNEDDS based on phospholipid complex technique was designed to improve the oral bioavailability of ASD.

There were two major obstacles in the development of APC-SNEDDS formulation. The first one was to entrap hydrophilic ASD into SNEDDS which was widely employed for poorly water-soluble drugs. ${ }^{24-26}$ Previous studies demonstrated that phospholipid complexes could improve the liposolubility and oral absorption of the hydrophilic drug. ${ }^{10,12,27}$ Thus, APC was prepared, and the liposolubility significantly increased 11.4-fold after formation of APC, which was verified by the solubility test in $n$-octanol. Different from other studies, the hydrophilicity increased $\sim 0.96$-fold

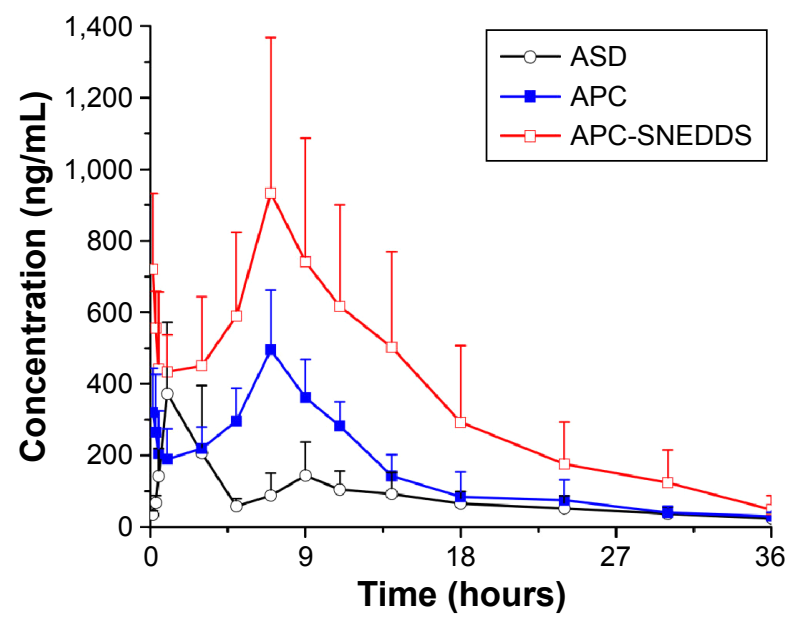

Figure 8 Plasma concentration-time profiles of ASD after oral administration of ASD, APC, and APC-SNEDDS formulation at a dose of $90 \mathrm{mg} / \mathrm{kg}$ (mean $\pm \mathrm{SD}, \mathrm{n}=6$ ). Abbreviations: ASD, Akebia saponin D; APC, Akebia saponin D-phospholipid complex; SNEDDS, self-nanoemulsifying drug delivery system; SD, standard deviation.
Table 6 Bioavailability and pharmacokinetic parameters of ASD after oral administration of ASD, APC, and APC-SNEDDS (mean $\pm \mathrm{SD}, \mathrm{n}=6$ )

\begin{tabular}{|c|c|c|c|}
\hline Parameter & ASD & APC & APC-SNEDDS \\
\hline$C_{\max } I(n g / m L)$ & $437.2 \pm 174.2$ & $342.3 \pm 154.2$ & $733.4 \pm 203.8^{* \ldots \#}$ \\
\hline$C_{\max } 2(\mathrm{ng} / \mathrm{mL})$ & $|80.5 \pm 75|$. & $549.7 \pm 113.5^{* *}$ & $985.8 \pm 366.6 * *, \#$ \\
\hline$T_{\max } l$ (hours) & $2.0 \pm 1.1$ & $0.195 \pm 0.068 * *$ & $0.195 \pm 0.068 * *$ \\
\hline$T_{\max } 2$ (hours) & $9.8 \pm 2.4$ & $8.0 \pm I .1$ & $6.667 \pm 0.82^{*, \#}$ \\
\hline $\begin{array}{l}\mathrm{AUC}_{0-36 \mathrm{~h}} \\
(\mathrm{ng} \cdot \mathrm{h} / \mathrm{mL})\end{array}$ & $3,019.4 \pm 963.5$ & $5,55 \mathrm{I} . \mathrm{I} \pm \mathrm{I}, 357.4^{* *}$ & $|3,038.4 \pm 5| 2 \mid, .7 * *, \#$ \\
\hline $\begin{array}{l}A^{A U C} C_{0-\infty} \\
\text { (ng.h/mL) }\end{array}$ & $3,491.9 \pm 1,227.7$ & $5,967.8 \pm 1,397.0 * *$ & $|3,528| \pm 5,.468.3 * *, \#$ \\
\hline$F(\%)$ & - & 183.8 & 431.8 \\
\hline
\end{tabular}

Notes: $* P<0.05$ and $* * P<0.01$ compared with ASD group. ${ }^{\# P}<0.05$ and ${ }^{\# P} P<0.01$ compared with APC group.

Abbreviations: ASD, Akebia saponin D; APC, Akebia saponin D-phospholipid complex; SNEDDS, self-nanoemulsifying drug delivery system; SD, standard deviation; $C$, maximum plasma concentration; $T$, time to maximum plasma concentration; AUC, the area under the plasma concentration-time curve; $F$, relative bioavailability.

compared with ASD. This result might have been caused by the transformation of polymorphs ${ }^{37}$ or solubilization by liposome micelles formed by APC after dissolving in water. ${ }^{38}$ The exact mechanism(s) needs to be further studied. In addition, different hydrophilic drug-loaded phospholipid complexes had different lipid solubility, ${ }^{10,27}$ so it was difficult to select appropriate absorption-enhancing oils which could dissolve a large amount of APC. In this study, Glyceryl monooleate (type 40) was found to have the largest dissolving capacity for APC among the oils tested. Moreover, Glyceryl monooleate (type 40) was a readily dispersible and absorbable solubilizing agent which could provide a triglyceridogenic substrate for efficient chylomicron synthesis and subsequent lymphatic transport. ${ }^{29}$ Thus, Glyceryl monooleate (type 40 ) was selected as the oil phase for the APC-SNEDDS to obtain an optimum drug loading and improve lymphatic transport of ASD.

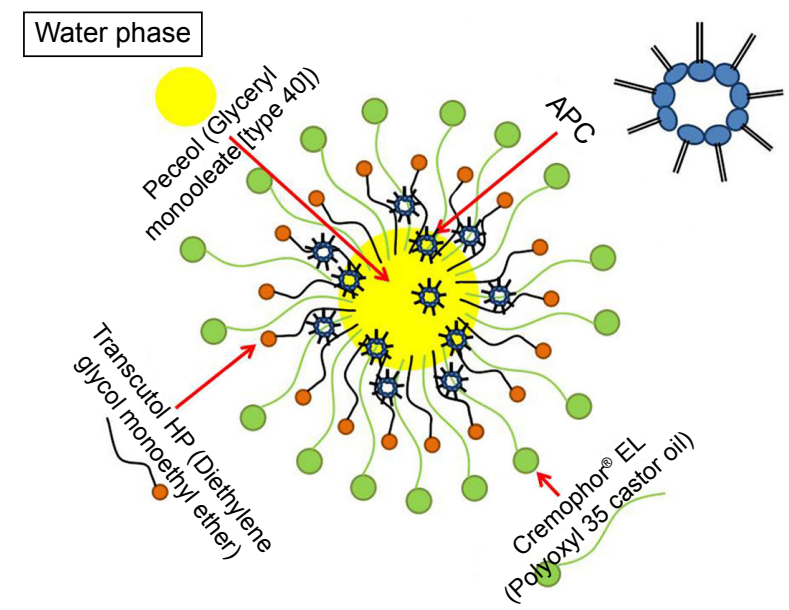

Figure 9 Proposed schematic diagram of APC-SNEDDS dissolved in distilled water. Abbreviations: APC, Akebia saponin D-phospholipid complex; SNEDDS, selfnanoemulsifying drug delivery system. 
According to the characterizations of APC-SNEDDS and definition of SNEDDS, a schematic diagram of APCSNEDDS after diluting with distilled water is proposed in Figure 9. Based on the studies conducted, we propose that APC could be completely embedded into the oil phase (Glyceryl monooleate [type 40]) and cosurfactant phase (Diethylene glycol monoethyl ether) to form an aggregate. Polyoxyl 35 castor oil mainly aided in the formation of fine droplets and improved the stability of the nanoemulsion through reducing the interfacial tension. The APC-SNEDDS with such a structure was proved to improve oral absorption of ASD via the pharmacokinetic studies in rats.

ASD was an amphipathic saponin which could selfassemble as micelles in gastrointestinal fluid with a large aggregate size. ${ }^{11}$ The formation of self-micelles might reduce the absorption rate and amount of ASD absorbed from gastrointestinal tract. ${ }^{11}$ APC and APC-SNEDDS were likely to prevent ASD from aggregation and increase its absorption rate and absorbed dose. This might be the reason that $T_{\max }$ was significantly shortened by the two new preparations. The oral absorption enhancement of APC probably resulted from the increase of liposolubility, effect on the biological membrane by phospholipids as a surfactant, and destruction of the self-micelles formed by ASD in gastrointestinal fluid. ${ }^{39}$ It was supposed that APC-SNEDDS enhanced the oral bioavailability of ASD via increasing intestinal permeability, inhibiting MRP-mediated efflux, preventing degradation by intestinal bacteria, and enhancing the lymphatic transport of ASD. The definite absorption mechanisms are rather complicated, and further investigations are in need.

Although APC-SNEDDS could significantly improve the oral absorption of ASD, the drug loading is limited. Screening for new absorption-enhancing oils which could dissolve more APC and adopting different technologies to entrap hydrophilic ASD into SNEDDS are promising strategies.

\section{Conclusion}

The present study demonstrated that hydrophilic ASD was successfully loaded into SNEDDS using the phospholipid complex technique. The oral absorption of ASD was significantly improved by APC and APC-SNEDDS. The exact absorption mechanisms were complicated and would be investigated in future studies. This study provided a new strategy to enhance the oral bioavailability of highly watersoluble but poorly absorbed saponins.

\section{Acknowledgments}

This project was financially supported by the National Natural Science Foundation of China (No 81403080 and
30730113) and the Natural Science Foundation of Jiangsu Province (No BK20140674).

\section{Disclosure}

The authors report no conflicts of interest in this work.

\section{References}

1. Zhou YQ, Yang ZL, Xu L, Li P, Hu YZ. Akebia saponin D, a saponin component from Dipsacus asper Wall, protects PC 12 cells against amyloid- $\beta$ induced cytotoxicity. Cell Biol Int. 2009;33(10): 1102-1110.

2. Niu Y, Li Y, Huang H, et al. Asperosaponin VI, a saponin component from Dipsacus asper Wall, induces osteoblast differentiation through bone morphogenetic protein-2/p38 and extracellular signal-regulated kinase 1/2 pathway. Phytother Res. 2011;25(11):1700-1706.

3. Li C, Tian J, Li G, et al. Asperosaponin VI protects cardiac myocytes from hypoxia-induced apoptosis via activation of the PI3K/Akt and CREB pathways. Eur J Pharmacol. 2010;649(1-3):100-107.

4. Gong LL, Wang ZH, Li GR, Liu LH. Protective effects of Akebia saponin D against rotenone-induced hepatic mitochondria dysfunction. J Pharmacol Sci. 2014;126(3):243-252.

5. Wu C, Ma P, Li PF. LC-MS/MS determination of oral bioavailability of Akebia saponin D in rat. J Beijing Normal Univ. 2014;50(1):62-65.

6. Zhou Y, Li W, Chen L, Ma S, Ping L, Yang Z. Enhancement of intestinal absorption of Akebia saponin D by borneol and probenecid in situ and in vitro. Environ Toxicol Pharmacol. 2010;29(3):229-234.

7. Yan L, Yang X, Meng Z, et al. Simultaneous quantification of Akebia saponin D and its five metabolites in human intestinal bacteria using ultraperformance liquid chromatography triple quadrupole mass spectrometry. J Chromatogr B Analyt Technol Biomed Life Sci. 2014; 971(15):81-88.

8. Wang L, Liu EW, Han LF. Study on bile excretion of effective component asperosaponin VI in Dipsacus asperoides. Tianjin J Trad Chin Med. 2012;30(11):681-684.

9. Han M, Fu S, Gao JQ, Fang XL. Evaluation of intestinal absorption of ginsenoside Rg1 incorporated in microemulsion using parallel artificial membrane permeability assay. Biol Pharm Bull. 2009;32(6): 1069-1074.

10. Xiong J, Guo J, Huang L, et al. The use of lipid-based formulations to increase the oral bioavailability of Panax notoginseng saponins following a single oral gavage to rats. Drug Dev Ind Pharm. 2008;34(1): $65-72$.

11. Xiong J, Guo J, Huang L, Meng B, Ping Q. Self-micelle formation and the incorporation of lipid in the formulation affect the intestinal absorption of Panax notoginseng. Int J Pharm. 2008;360(1-2): 191-196.

12. Zhang $\mathrm{Q}, \mathrm{He} \mathrm{N}$, Zhang $\mathrm{L}$, et al. The in vitro and in vivo study on selfnanoemulsifying drug delivery system (SNEDDS) based on insulinphospholipid complex. J Biomed Nanotechnol. 2012;8(1):90-97.

13. Li CL, Deng YJ. Oil-based formulations for oral delivery of insulin. J Pharm Pharmacol. 2004;56(9):1101-1107.

14. Wang S, Su R, Nie S, et al. Application of nanotechnology in improving bioavailability and bioactivity of diet-derived phytochemicals. J Nutr Biochem. 2014;25(4):363-376.

15. Li C, Zhang J, Zu YJ, et al. Biocompatible and biodegradable nanoparticles for enhancement of anti-cancer activities of phytochemicals. Chin J Nat Med. 2015;13(9):641-652.

16. Qhattal HSS, Wang S, Salihima T, Srivastava SK, Liu X. Nanoemulsions of cancer chemopreventive agent benzyl isothiocyanate display enhanced solubility, dissolution, and permeability. J Agric Food Chem. 2011;59(23):12396-12404.

17. Voruganti S, Qin JJ, Sarkar S, et al. Oral nano-delivery of anticancer ginsenoside 25-OCH3-PPD, a natural inhibitor of the MDM2 oncogene: nanoparticle preparation, characterization, in vitro and in vivo anti-prostate cancer activity, and mechanisms of action. Oncotarget. 2015;6(25):21379-21394. 
18. de Pace RC, Liu X, Sun M, et al. Anticancer activities of (-)-epigallocatechin-3-gallate encapsulated nanoliposomes in MCF7 breast cancer cells. J Liposome Res. 2013;23(3):187-196.

19. Sun M, Nie S, Pan X, Zhang R, Fan Z, Wang S. Quercetin-nanostructured lipid carriers: characteristics and anti-breast cancer activities in vitro. Colloids Surf B Biointerfaces. 2014;113(13):15-24.

20. Zhang J, Nie S, Wang S. Nanoencapsulation enhances epigallocatechin3-gallate stability and its antiatherogenic bioactivities in macrophages. J Agric Food Chem. 2013;61(38):9200-9209.

21. Date AA, Desai N, Dixit R, Nagarsenker M. Self-nanoemulsifying drug delivery systems: formulation insights, applications and advances. Nanomedicine. 2010;5(10):1595-1616.

22. Hanke U, May K, Rozehnal V, Nagel S, Siegmund W, Weitschies W. Commonly used nonionic surfactants interact differently with the human efflux transporters ABCB1 (p-glycoprotein) and ABCC2 (MRP2). Eur J Pharm Biopharm. 2010;76(2):260-268.

23. Zhang J, Peng Q, Shi S, et al. Preparation, characterization, and in vivo evaluation of a self-nanoemulsifying drug delivery system (SNEDDS) loaded with morin-phospholipid complex. Int J Nanomedicine. 2011; 2011(6):3405-3414.

24. Rashid R, Kim DW, Yousaf AM, et al. Comparative study on solid selfnanoemulsifying drug delivery and solid dispersion system for enhanced solubility and bioavailability of ezetimibe. Int J Nanomedicine. 2015; 10(1):6147-6159.

25. Chen CH, Chang CC, Shih TH, Aljuffali IA, Yeh TS, Fang JY. Selfnanoemulsifying drug delivery systems ameliorate the oral delivery of silymarin in rats with Roux-en-Y gastric bypass surgery. Int $J$ Nanomedicine. 2015;10(1):2403-2416.

26. Zhang L, Zhang L, Zhang M, et al. Self-emulsifying drug delivery system and the applications in herbal drugs. Drug Deliv. 2015;22(4): 475-486.

27. Ruan J, Liu J, Zhu D, et al. Preparation and evaluation of self-nanoemulsified drug delivery systems (SNEDDSs) of matrine based on drug-phospholipid complex technique. Int J Pharm. 2010;386(1-2): 282-290.
28. Heshmati N, Cheng X, Eisenbrand G, Fricker G. Enhancement of oral bioavailability of E804 by self-nanoemulsifying drug delivery system (SNEDDS) in rats. J Pharm Sci. 2013;102(10):3793-3799.

29. Hauss DJ, Fogal SE, Ficorilli JV, et al. Lipid-based delivery systems for improving the bioavailability and lymphatic transport of a poorly water-soluble LTB4 inhibitor. J Pharm Sci. 1998;87(2):164-169.

30. Wasan EK, Bartlett K, Gershkovich P, et al. Development and characterization of oral lipid-based Amphotericin B formulations with enhanced drug solubility, stability and antifungal activity in rats infected with Aspergillus fumigatus or Candida albicans. Int J Pharm. 2009;372(1-2):76-84.

31. Zhou H, Wan J, Wu L, et al. A new strategy for enhancing the oral bioavailability of drugs with poor water-solubility and low liposolubility based on phospholipid complex and supersaturated SEDDS. PLoS One. 2013;8(12):e84530.

32. Nielsen FS, Petersen KB, Mullertz A. Bioavailability of probucol from lipid and surfactant based formulations in minipigs: influence of droplet size and dietary state. Eur J Pharm Biopharm. 2008;69(2):553-562.

33. Gao Z, Choi H, Shin H, et al. Physicochemical characterization and evaluation of a microemulsion system for oral delivery of cyclosporine A Int J Pharm. 1998;161(1):75-86.

34. Anton N, Vandamme TF. Nanoemulsions and microemulsions: clarifications of the critical differences. Pharm Res. 2011;28(5):978-985.

35. Gao S, Basu S, Yang Z, Deb A, Hu M. Bioavailability challenges associated with development of saponins as therapeutic and chemopreventive agents. Curr Drug Targets. 2012;13(14):1885-1899.

36. Sparg SG, Light ME, van Staden J. Biological activities and distribution of plant saponins. J Ethnopharmacol. 2004;94(2-3):219-243.

37. Wang QH, Yang XL, Xiao W, et al. Microcrystalline preparation of akebia saponin $\mathrm{D}$ for its bioavailability enhancement in rats. Am JChin Med. 2015;43(3):513-528.

38. Song Y, Zhuang J, Guo J, Xiao Y, Ping Q. Preparation and properties of a silybin-phospholipid complex. Pharmazie. 2008;63(1):35-42.

39. Li J, Wang XL, Zhang T, et al. A review on phospholipids and their main applications in drug delivery systems. Asian J Pharm Sci. 2015; 10(2):81-98.
International Journal of Nanomedicine

\section{Publish your work in this journal}

The International Journal of Nanomedicine is an international, peerreviewed journal focusing on the application of nanotechnology in diagnostics, therapeutics, and drug delivery systems throughout the biomedical field. This journal is indexed on PubMed Central,

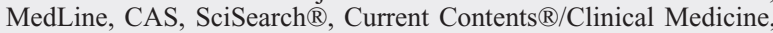

\section{Dovepress}

Journal Citation Reports/Science Edition, EMBase, Scopus and the Elsevier Bibliographic databases. The manuscript management system is completely online and includes a very quick and fair peer-review system, which is all easy to use. Visit http://www.dovepress.com/ testimonials.php to read real quotes from published authors. 